\title{
The Basic Research on the Dye-Sensitized Solar Cells (DSSC)
}

\author{
Arini Nuran Binti Zulkifili, Terauchi Kento, Matsutake Daiki, and Akira Fujiki
}

\begin{abstract}
The dye-sensitized solar cell (DSSC) is a new type of solar cell which converts the visible light into electricity by using the photoelectrochemical system. It is based on the sensitization of the wide band gap semiconductors which is made up of a sandwich-liked structure that consists of a semiconductor formed between a photo-sensitized anode and an electrolyte. In this research, we focused on the $\mathrm{TiO}_{2}$ photoelectrode by evaluating the particle size of titania, determining the effects of molecular binder PEG towards $\mathrm{TiO}_{2}$ paste preparation, as well as the effects of natural dye by comparing the blueberry, gardenia blue and yellow and red yeast dye, and evaluating the effect of the multilayer of $\mathrm{TiO}_{2}$.
\end{abstract}

Index Terms-Dye-sensitized solar cell, nano-particles $\mathrm{TiO}_{2}$, natural coloring, polyethylene glycol (PEG).

\section{INTRODUCTION}

The global energy consumption is increasing year by year. In 1998 , it was $12.7 \mathrm{TW}$, but in 2050 , it is expected to be around 26.4 to $32.9 \mathrm{TW}$ and in 2100 , it will increase up to 46.3 to $58.7 \mathrm{TW}$ [1]. The yearly increase in global energy consumption will result in the rise of demands towards natural resources such as coal, petroleum and natural gas. These natural resources will take thousand of years to form and it cannot be replaced as fast as they are being consumed. Therefore, it is possible that problems may arive where we will be facing the shortage of resources which at the same time will caused in the rise of the harvesting expenses. As a result, the reliability on the other sources of energy, which is renewable will also rise.

In this generation, a solar cell, which also known as photovoltaic cell is one of the promising options of renewable energy. A solar cell is a photonic device that converts photons with specific wavelengths to electricity. Solar cell is divided into two groups which are the crystalline silicon and thin film (Fig. 1). The first and second generation of photovoltaic cells are mainly constructed from semiconductors including crystalline silicon, III-V compounds, cadmium telluride and copper indium selenide/sulfide [2].

The dye-sensitized solar cells (DSSC) which belong to the thin film group, emerged as a new class of low cost energy conversion devices with simple manufacturing procedures. Incorporation of dye molecules in some wide bandgap semiconductor electrodes was a key factor in developing

Manuscript received June 11, 2014; revised August 24, 2014.

Arini Nuran Binti Zulkifili and Fujiki Akira are with the School of Engineering, Shibaura Institute of Technology (SIT), 307 Fukasaku, Minuma Ward, Saitama City, Saitama 337-8570, Japan (e-mail: md13004@shibaura-it.ac.jp, a-fujiki@sic.shibaura-it.ac.jp).

Terauchi Kento is with Yazaki Co., Japan.

Matsutake Daiki is with Fujitsu Tokki System Limited, Japan. photoelectrochemical solar cells. Since the low cost solar cells have been the subject of intensive research work for the last three decades [3], Michael Gratzel and coworkers at the Ecole Polytechnique Federale de Lausene [4] succeeded to produce "Gratzel Cell" or which known as dye-sensitized solar cells that imitate the photosynthesis process by sensitizing a nanocrystalline $\mathrm{TiO}_{2}$ film using novel $\mathrm{Ru}$ bipyridl complex [5]. (Table I shown the comparison between two solar cells).

Therefore, the dye sensitized solar cells (DSSC) (Fig. 2(a)) have been intensively studied as a new type of solar cells which composed of nanocrystalline porous semiconductor electrode which absorbed dye, a counter electrode and an electrolyte of iodide-triiodide ions. It is a device for the conversion of visible light into electricity, based on photosensitization produced by the dyes on the wide band-gap mesoporous metal oxide semiconductors. This sensitization is due to the dye absorption of a part of the visible light spectrum. The sensitized dye works by absorbing the sunlight which then convert it into electrical energy.

The operation principle of DSSC is displayed in Fig. 2(b). It can be divided into following flows [6]:

1) An electron passed through a cycle of excitation;

2) Injection in the $\mathrm{TiO}_{2}$, and the iodine reduction occur at the counter electrode and the electron passing through $\mathrm{TiO}_{2}$ to the electrode;

3) External work of electron;

4) Diffusion in the electrolyte;

5) Regeneration of the oxidized dye.

Recently, titanium dioxide $\left(\mathrm{TiO}_{2}\right)$ has attracted attention from researchers worldwide due to its potential applications in environmental protection and energy generation [5] and has been applied largely in DSSC due to its nanocrystalline mesoporous nature that translates to high surface area for dye adsorption. The absorbed dye molecules can then be excited by the solar energy to generate electron-hole pairs that are subsequently separated and transported within the lattice of $\mathrm{TiO}_{2}$ [7]. The absorption spectrum of the dye and the anchorage of the dye to the surface of $\mathrm{TiO}_{2}$ are important parameters in determining the efficiency of the cell [8]. Since the dye plays an important role in absorbing visible light and transferring photon energy into electricity, much attention has been paid to survey the effective sensitizer dyes [9].

Several metal complexes and organic dyes have been synthesized and used as sensitizers including porphyrins [10], platinum complex [11] and others. Ru-based complexes sensitizers have been widely used because they have better efficiency and high durability. However, these advantages are offset by their high cost and tend to undergo degradation in the presence of water [12]. Besides, it is also regarded as highly toxic and carcinogenic. 
TABLE I: COMPARISON BETWEEN SEMICONDUCTOR BASED SOLAR CELL AND THE DYE-SENSITIZED SOLAR CELL (DSSC) [3]

\begin{tabular}{lll}
\hline & Semiconductor Solar Cells & Dye-Sensitized Solar Cells \\
\hline Transparency & Opaque & Transparent \\
Pro-environment (material \& process) & Normal & Great \\
Power generation cost & High & Low \\
Power generation efficiency & High & Normal \\
Color & Limited & Various \\
\hline \hline
\end{tabular}

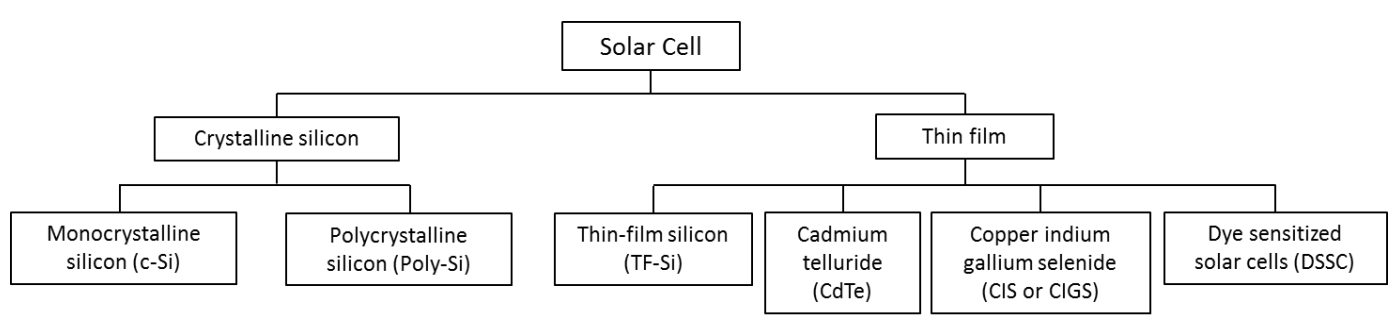

Fig. 1. Type of solar cells.

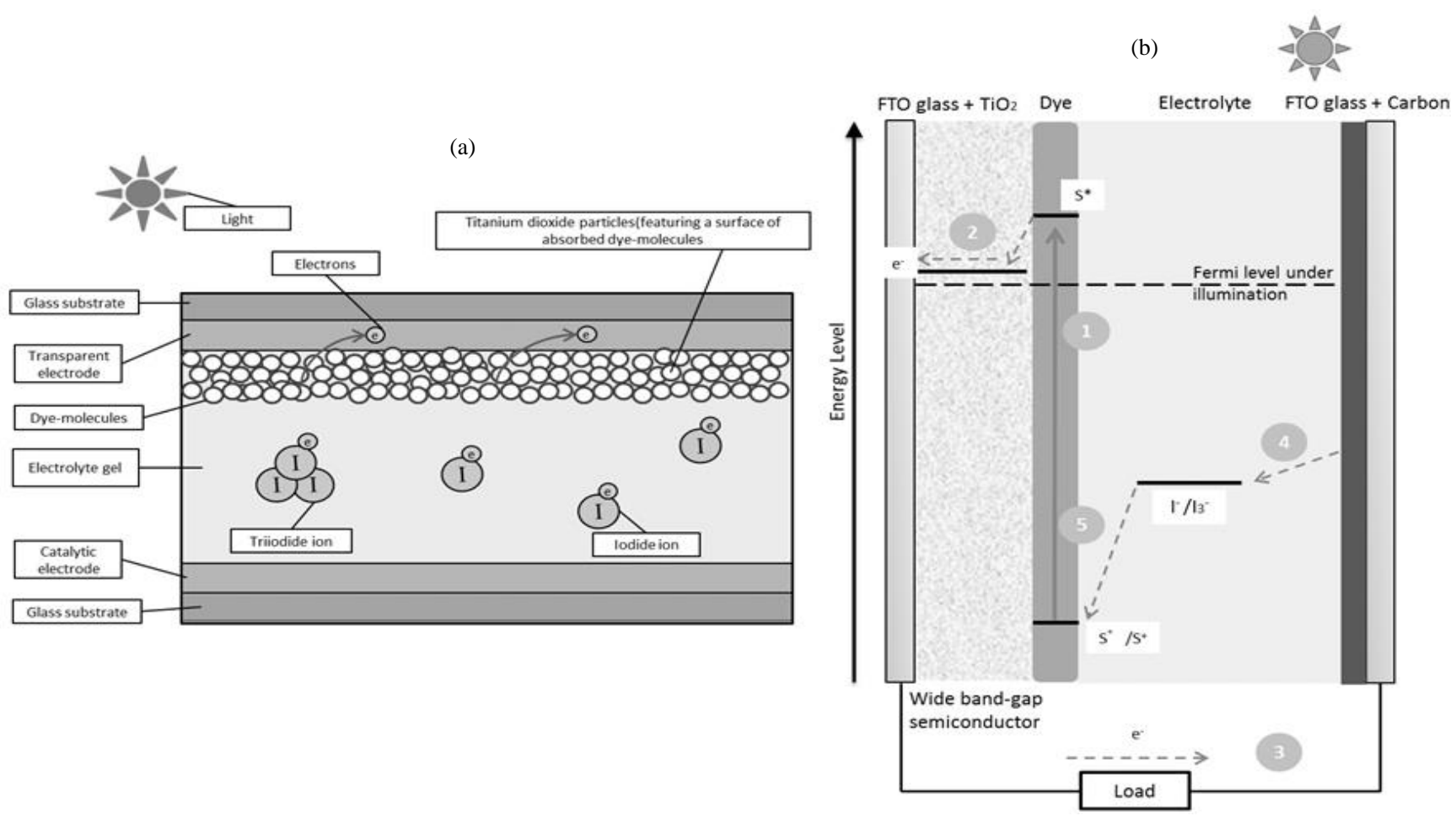

Fig. 2. (a) The structure of DSSC and (b) The mechanism of DSSC.

Therefore, in order to overcome these problems, we chose to use natural pigments as sensitizing dye. Unlike the artificial dyes, the natural dye is easily available, easy to prepare, low cost, non-toxic, environmental friendly and fully biodegradable [13]. In most cases, their photo activity is due to the presence of anthocyanin family [14]-[16]. Anthocyanins from strongly colored fruits, leaves and flowers are capable of attaching to $\mathrm{TiO}_{2}$ surface and inject electrons into the conduction band of $\mathrm{TiO}_{2}$ [17], [18]. In DSSC, natural pigments extracted from fruits and vegetables such as anthocyanins which is the blueberry, had been proven to be applicable of producing high power efficieny. However, gardenia (blue and yellow) [19] and red yeast are still new and need further research.

Besides that, in order to have a crack free and high efficiency of $\mathrm{TiO}_{2}$ photoelectrode, we need to use a binder. In this current research, we chose to use polyethylene glycol (PEG) as the binder. PEG is a non-ionic surfactant commonly utilized in thin film fabrication as a structure directing agent, owing to its favorable burnout characteristics, low glass transition temperature and good solubility in water and organic solvents [20]-[24]. The presence of binder in an appropriate amount can produce a crack free photoelectrode besides improving the strength and density of the photoelectrode after sintering [25], [26].

By combining the best condition for each parameter, we conducted the final experiment which is the multilayer $\mathrm{TiO}_{2}$ photoanode. The power produce of a DSSC is depending on the thickness of the photoanode. Hence, the experiment was conducted to determine the maximum thickness of the $\mathrm{TiO}_{2}$ photoanode since the multilayer $\mathrm{TiO}_{2}$ research is still new and need further research.

\section{EXPERIMENTAL PROCEDURE}

\section{A. Examined Materials}

For fabrication of DSSC, $\mathrm{TiO}_{2}$ powder (Ishihara Sangyo Company, ST-01), acetic acid (Kanto Chemical Company), pure water, polyethylene glycol 400mol (Wako Pure 
Chemical Industries), polyethylene glycol 20000mol (Wako Pure Chemical Industries), acetylacetone (Kanto Chemical Company, JIS K 8027), iodine electrolyte, graphite carbon pencil, and FTO (Fluorine doped $\mathrm{SnO}_{2}$ coated glasses) were used in this research. For the dye, gardenia - blue (Gaban GSO Company), gardenia - yellow (Gaban GSO Company), red yeast (Gaban GSO Company) and frozen blueberries were used.

Experimental steps were done in three parts, which are the preparation of the cathode electrode $\left(\mathrm{TiO}_{2}\right.$ photoelectrode), preparation of the anode electrode (carbon counter electrode) and the preparation of the dye-sensitized solution.

\section{B. Preparation Method}

The DSSCs were composed of a $\mathrm{TiO}_{2}$ photoelectrode which were immersed in a dye solution, a Carbon counter electrode and the liquid electrolyte. Therefore, in these experiments, we divided the preparation method in three methods which based on each layer that require different preparation method.

The $\mathrm{TiO}_{2}$ films were made by spreading $\mathrm{TiO}_{2}$ pastes on the fluorine-doped $\mathrm{SnO}_{2}$ conducting glass (FTO) by the spin coating technique. $\mathrm{TiO}_{2}$ paste were prepared by mixinggrounding the $\mathrm{TiO}_{2}$ powder with distilled water, acetic acid, acetylacetone and polyethylene glycol (PEG). Extensive stirring were proceeded to ensure complete dispersion of $\mathrm{TiO}_{2}$ nanoparticles and to facilitate the spreading of the colloid on FTO glass [9]. Droplets of each paste were placed onto the FTO glass, on the turning table of a spin coater. Adhesive tapes were placed on the edges of FTO glass to form a guide to spread the pastes for about 10 seconds. Then, the $\mathrm{TiO}_{2}$ was sintered at $450^{\circ} \mathrm{C}$ for 60 minutes. The resulted electrode were then cooled down to $80^{\circ} \mathrm{C}$. Thickness of the $\mathrm{TiO}_{2}$ film was controlled by multiple coating processes in which the coated substrates were subjected repeatedly to spin-coating and drying steps.

To prepare the Carbon counter electrode, the FTO glass was wiped with ethanol. Then, the FTO glass surface was colored by using graphite carbon pencil. After that, the surface was checked to ensure that there was no space that the carbon did not cover.

The preparation of the dye-sensitized solutions varries based on the dye chosen. For the anthocyanin (blueberry) dye, 20 frozen blueberries were left to defroze. No water was added into the solution. Cathode electrode was then immersed in the dye solution for six hours. After that, the surface of the $\mathrm{TiO}_{2}$ photoelectrodes were cleaned by using the ethanol to ensure that there were no blueberry remained on top of the $\mathrm{TiO}_{2}$ surface. For gardenia-blue dye and gardenia-yellow dye, 20 droplets of each dye were mixed with $15 \mathrm{ml}$ of pure water. It was then left for six hours for gardenia-blue dye and four hours for gardenia-yellow solution. All of these were carried out at $21^{\circ} \mathrm{C}$, without the presence of light. The TiO2 photoelectrodes were then taken out of the dye solution, and dried using the dryer for two minutes at temperature around $40^{\circ} \mathrm{C}$ to $42^{\circ} \mathrm{C}$.

In the preparation of liquid electrolyte, $10 \mathrm{ml}$ of ethylene glycol was added into a beaker. Then, $0.127 \mathrm{~g}$ of iodine $\left(\mathrm{I}_{2}\right)$ was added into the beaker containing ethylene glycol. After that, $0.83 \mathrm{~g}$ of potassium iodide was added. By using the glass rod, the mixture was mixed until there was no grain of iodine and potassium iodide can be seen.

\section{DSSC Assembling}

The cathode electrode and the anode electrode were put together, overlapping each other, and a space at the end of each electrode was made. Next, both electrodes were fasten using the double clip. Three drops of iodide solution were added at the end of the electrode and the solutions were spread over the entire electrode. Then, the remaining iodide solution were wiped off using cotton swab soaked with alcohol. After that, a tester with crocodile clip were attached at both ends of the electrode. The experiment was conducted under the halogen lamp $(110 \mathrm{~V}, 250 \mathrm{~W})$.

\section{RESUlTS AND DISCUSSION}

In this research, we conducted a few experiments in order to find the best power production for this research. The experiments were divided into four parts, which is the titania particle size evaluation, the effect of molecular binder PEG to $\mathrm{TiO}_{2}$ paste, the effect of dye and the thickness of $\mathrm{TiO}_{2}$ layer.

\section{A. Titania Particle Size Evaluation Experiment}

Based on Table II, as the size of the particle increases, the contact area between the conductive surface and the dispersion is insufficient and this will decrease the Coulomb force between the titania particles, and thus, will lead to the inconstant film thickness when being applied using the spin coating technique as the titanium dioxide particles does not dispersed completely. After the film application, we can see that the film thickness is not constant besides having cracks and holes on the surface. This will then lead to the low and unstable power generation. The presence of cracks, holes and inconstant film thickness made the sintering process difficult which made the movement of electron throughout the titania electrode is limited.

TABLE II: TITANIA PARTICLE SiZE EVALUATION

\begin{tabular}{ccccc}
\hline \hline $\begin{array}{c}\text { Particle } \\
\text { size } \\
{[\mathbf{n m}]}\end{array}$ & $\begin{array}{c}\text { Uniformity } \\
\text { of the film } \\
\text { thickness }\end{array}$ & $\begin{array}{c}\text { Surface } \\
\text { condition }\end{array}$ & Sinterability & $\begin{array}{c}\text { Power } \\
\text { Stability }\end{array}$ \\
\hline $\mathbf{7}$ & $\Delta$ & 0 & $\bigcirc$ & $\bigcirc$ \\
$\mathbf{6 0}$ & $\mathrm{x}$ & $\mathrm{x}$ & $\Delta$ & $\Delta$ \\
$\mathbf{1 6 0}$ & $\mathrm{x}$ & $\mathrm{x}$ & $\mathrm{x}$ & $\mathrm{x}$ \\
\hline \hline (): Excellent & $\circ:$ Good & & & \\
$\triangle:$ : Acceptable & $\times$ : Not acceptable & &
\end{tabular}

From the experiment conducted, we can conclude that the best $\mathrm{TiO}_{2}$ powder's particle size is $7 \mathrm{~nm}$. It has the best condition for sintering and the most stable power produced besides having the uniformity of the film thickness and good surface condition. The mesoporous photoelectrodes films composed of small-sized $\mathrm{TiO} 2$ nanocrystalline particles have the advantages of providing a large surface for greater dye adsorption and facilitating electrolyte diffusion within their pores [27].

\section{B. The Influence of Binder Molecular Weight (PEG) towards the Power Production}

Based on result in chapter $\mathrm{A}$, the titania particles with the 
diameter of $7 \mathrm{~nm}$ was evaluate to have the best characteristics to be applied for this current research. Therefore, by using $7 \mathrm{~nm}$ titania particles, we conducted experiment to determine the influence of the binder molecular weight (PEG) towards the power produced.

From the graph in Fig. 3, we can conclude that the higher molarity of the molecular binder, which is PEG 20000 mol will produce a higher current density production, but with low circuit voltage compared to PEG 400mol. However, the lower molarity, which is the PEG 400mol will produce a higher circuit voltage production, but with lower current density production.

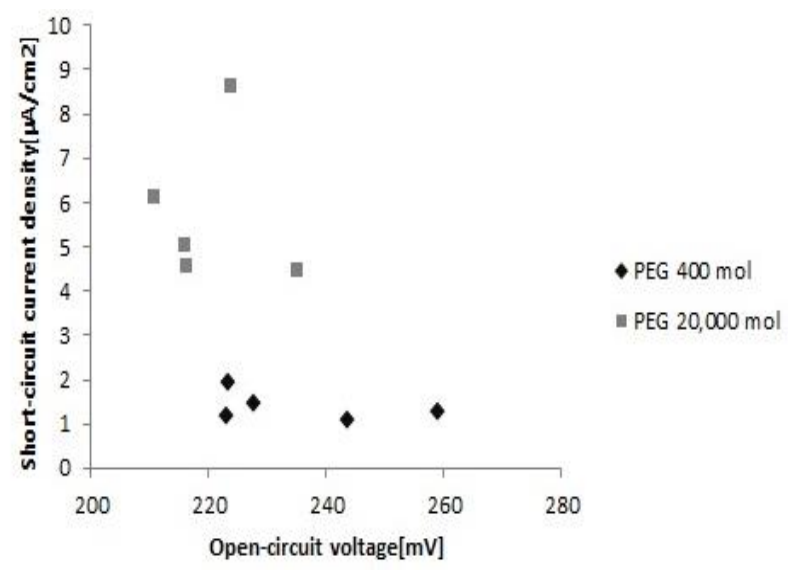

Fig. 3. The voltage and current distribution for PEG400mol and PEG20,000mol.

From the observation during the application process via spin coating method, the PEG 400mol layer was too thin. Besides that, we can see that the final film showed the presence of large agglomerates and cracks after sintering. From these, we can suggest that the length of chains was insufficient to produce a stable viscous polymeric template, which led to the formation of the non-uniform films.

On the other hand, it is considered that a high molecular weight is required to enhance the binder strength [28]. Therefore, the long chain binder, PEG 20000mol was chosen. The agglomeration of $\mathrm{TiO}_{2}$ particles was still occurring, but not as bad as presence in PEG 400mol. It is suggested that the higher molecular weight will have better interconnected network of $\mathrm{TiO}_{2}$ particles, which are important for providing good photocatalytic performance in DSSC [29].

Since this experiment was conducted without using dye as a sensitizer, the result obtained have large variability. However, for the power produced (Fig. 4), PEG 20000mol produced about three to four times larger power than the PEG 400mol. From this experiment, we can conclude that a high molecular weight, which is the PEG $20000 \mathrm{~mol}$ is most suitable for current research. In the upcoming research, we will try to use another molecular weight binder such as PEG 6000mol that is believe to form $\mathrm{a} \mathrm{TiO}_{2}$ film without the presence of cracks and having sufficient pores throughout the $\mathrm{TiO}_{2}$ films besides having interconnected network of $\mathrm{TiO}_{2}$ particles [29].

\section{The Influence of Each Coloring towards the Power Production}

When the $\mathrm{TiO}_{2}$ photoelectrode is immersed into the dye solution, the power that is produced will also increase. However, the power produced will be depending on the type of dye used. We chose to use the natural based dye such as blueberry, gardenia blue and yellow and red yeast in our current research. From the results obtained in Fig. 5, the highest power produced was from the bluberry, followed by gardenia yellow, gardenia blue and red yeast.

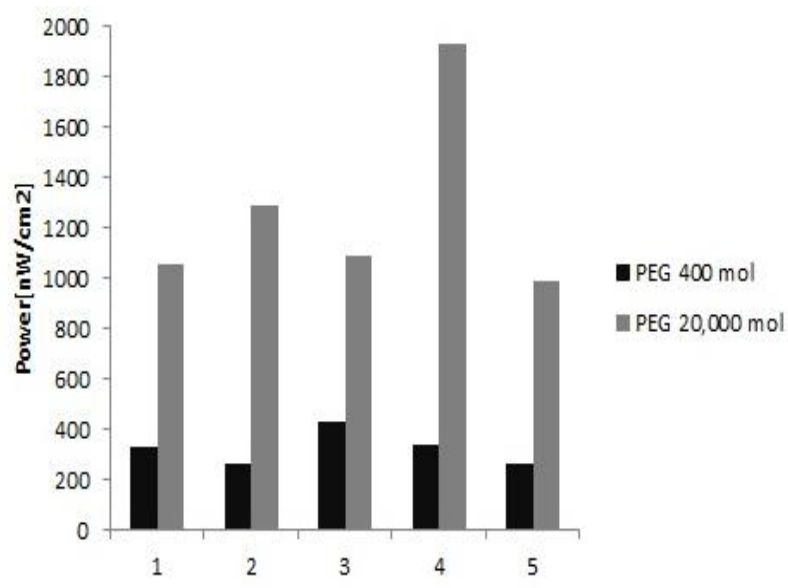

Fig. 4. The power produced for each PEG400mol and PEG20,000mol.

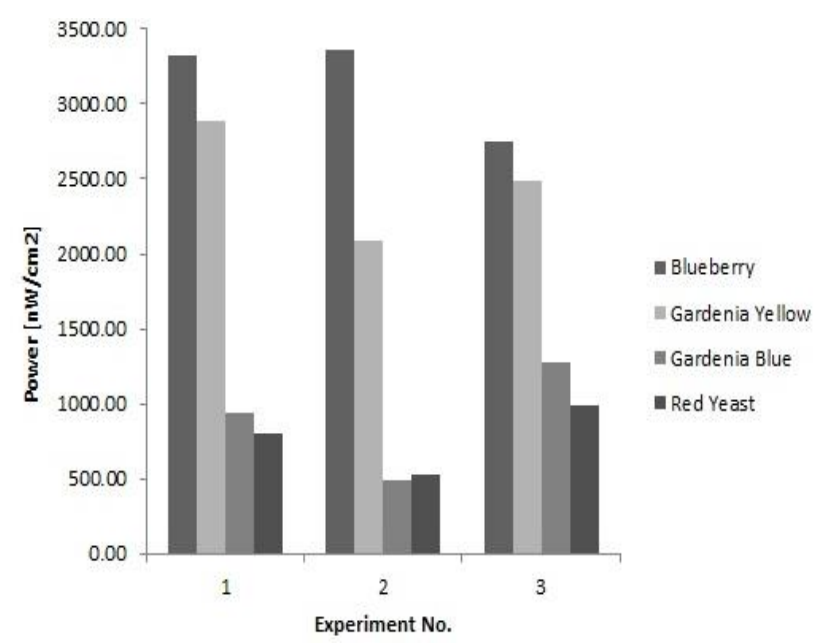

Fig. 5. The power produced based on each dye used.

Fig. 6(a) shows the structure of the anthocyanin dye that were adsorbed into the titanium metal centres on the titanium dioxide surface. It can transfer the excited electrons to the titanium dioxide and then transfer the electrons to the semiconductor plate [30]. Fig. 6(b) shows the chemical structure of the gardenia-based dye. Both blue and yellow have the same chemical structure. However, the power production was different as this might related to the color spectrum in the light absorption process.

It is generally accepted that the chemical adsorption of these dye takes place due to the condensation of alcoholic-bound protons with the hydroxyl groups that is present on the surface of the nanostructured $\mathrm{TiO}_{2}$ thin films [31]. This chemical attachment affects the energy levels of the highest occupied molecular level (HOMO) and the lowest unoccupied molecular level (LUMO) of the dye molecule [32], which eventually affects the band gap of these materials and this results in a shift in the absorption band of the absorption spectra [30]. 


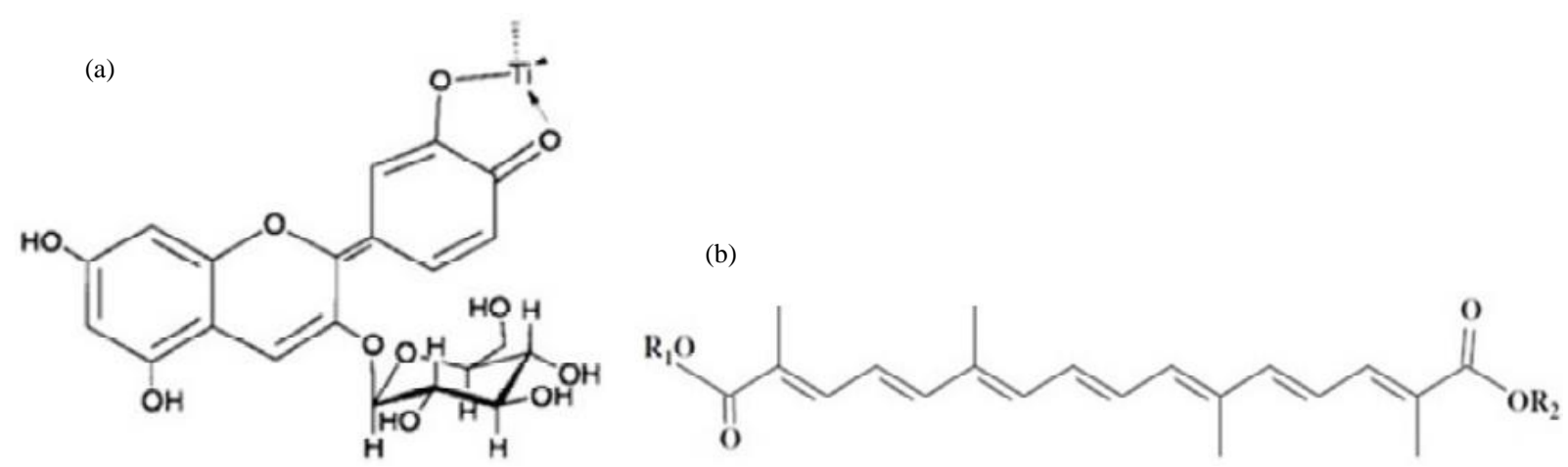

Fig. 6. (a) The chemical structure of anthocyanin-blueberry [31] and (b) the chemical structure of gardenia [19].

\section{The Influence of $\mathrm{TiO}_{2}$ Multilayer (Number of Layer) towards the Power Production}

The results produced (Fig. 7) shows that as the layer of $\mathrm{TiO}_{2}$ increases, the power produced will also increase. The sufficient film thickness will create the large pore size and enough space that will allow more redox electrolyte to diffuse into the film.

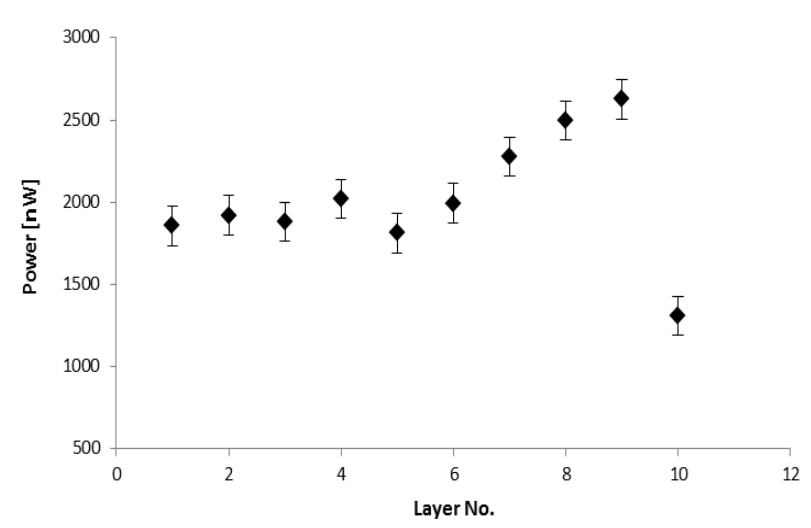

Fig. 7. The average of power produced as the thickness (layer) increases.

It is noted that the amount of dye absorbed for $\mathrm{TiO}_{2}$ increases with the film thickness. The photocurrent generated by the solar cell is directly proportional to the amount of the dye adsorbed on $\mathrm{TiO}_{2}$ film [33]. This explains that more dye molecules are attached to the increased surface of $\mathrm{TiO}_{2}$. Then, it can generate more electrons and improve the electron transport. The circuit voltage is almost the same, while the current density increases as the thickness of the $\mathrm{TiO}_{2}$ layer increases. This brings about the improvement of the efficiency.

Dyes in the $\mathrm{TiO}_{2}$ layers will build up with the increasing thickness and results in the increasing of the photocurrent. However, at some point, thicker $\mathrm{TiO}_{2}$ layers will result in a decrease in the transmittance of $\mathrm{TiO}_{2}$ layers and thus reduce the incident light intensity to dyes.

Moreover, the charge transfer resistance increases with the increasing thickness of $\mathrm{TiO}_{2}$ layers. In addition, the charge recombination between electrons injected from the excited dye to the conduction band of $\mathrm{TiO}_{2}$ and the $\mathrm{I}_{3}{ }^{-}$ions in the electrolyte will be higher in thicker $\mathrm{TiO}_{2}$ layer [34]

\section{CONCLUSION}

There are many factors that will influence the performance and efficiency of a DSSC such as the chosen of the materials, coloring and the thickness of the electrode. From all of the experiments conducted, we discovered that the particle size of $\mathrm{TiO}_{2}$ is the best at $7 \mathrm{~nm}$ and suitable to be applied for the current research. Therefore, all the next consecutives experiments will be conducted by using the $7 \mathrm{~nm} \mathrm{TiO}_{2}$.

We also discovered that in the preparation of $\mathrm{TiO}_{2}$ photoanode, the suitable binder was the higher molarity PEG, which is the $20000 \mathrm{~mol}$. By using the 20000 mol PEG, the most suitable natural dye was the anthocyanin(blueberry) and the optimum thickness by layer was at the $9^{\text {th }}$ layer. Thus, we will continue the experiment by combining all the best condition that we discovered, with an intention to continue to improve the current performance of the natural-dye-based DSSC and achieve the objectives of this research.

\section{REFERENCES}

[1] R. Eisenberg and D. G. Nocera, "Preface: overview of the forum on solar and renewable energy," Inorganic Chemistry, vol. 44, p. 6799, 2005.

[2] H. Kohjiro and A. Hironori, "Dye-sensitized solar cells," in Handbook of Photovoltaic Science and Engineering, A. Luque and S. Hegedus Eds. John Wiley \& Sons, ch. 15.

[3] K. E. Jasim, "Dye sensitized solar cells-working principles, challenges and oppurtunities," Solar Cells - Dye-Sensitized Devices, November 9, 2011.

[4] M. Gratzel, "Dye sensitized solar cells," Journal of Photochemistry and Photobiology C: Photochemistry Reviews, vol. 4, issue 2, pp. 145-153, 2003.

[5] L. Saadoun et al., "Synthesis and photocatalytic activity of mesoporous anatase prepared from tetrabutylammonium-titania composites," Material Research Bulletin, vol. 35, no. 2, pp. 193-202, 2000 .

[6] M. Sokolsky and J. Cirak, "Dye-sensitized solar cells: materials and processes," Acta Electrotechnica et Informatica, vol. 10, pp. 78-81, 2010.

[7] B. O'Regan and M. Grätzel, "A low-cost, high-efficiency solar cell based on dye-sensitized colloidal $\mathrm{TiO}_{2}$ films," Nature, vol. 353, no. 24, pp. 737-740, 1991.

[8] S. Hao and J. Wu, "Natural dyes as photosensitizers for dye-sensitized solar cell," Solar Energy, vol. 80, no. 2, pp. 209-214, 2006.

[9] T. Y. Kim and K. H. Park, "Adsorption equilibrium and kinetics of gardenia blue on $\mathrm{TiO}_{2}$ photoelectrode for DSSC," International Journal of Photoenergy, 2014.

[10] F. Odobel et al., "Porphyrin dyes for $\mathrm{TiO}_{2}$ sensitization," Journal of Materials Chemistry, vol. 13, pp. 502-510, 2003.

[11] A. Islam et al., "Dye sensitization of nanocrystalline titanium dioxide with square planar platinum(II) diimine dithiolate complexes," Inorganic Chemistry, vol. 40, pp. 5371-5380, 2001.

[12] D. Zhang et al., "Pigments for dye-sensitized solar cells," Photochem Photobiol A, vol. 195, pp. 72-80, 2008.

[13] C. Giuseppe and D. M. Gaetano, "Red sicilan orange ad purple eggplant fruits as natural sensitizers for dye-sensitized solar cells," Sol Energy Mater Sol Cells, vol. 92, pp. 1341-1346, 2008.

[14] N. J. Cherepy, G. P. Smestad, M. Gratzel, and J. Z. Zhang, "Ultrafast electron injection: implications for a photoelectrochemical cell 
utilizing an anthocyanin dye-sensitized $\mathrm{TiO}_{2}$ nanocrystalline electrode," J. Phys Chem B., vol. 101, pp. 9342-9351, 1997.

[15] G. P. Smestad, "Education and solar conversion: demonstrating electron transfer," Sol. Energy Mater Sol Cells, vol. 55, pp. 157-178, 1998.

[16] Q. Dai and J. Rabbani, "Photosensitization of nanocrystalline $\mathrm{TiO}_{2}$ films by anthocyanin dyes," J. Photochem Photobiol A, vol. 148, pp. 17-24, 2002.

[17] M. Rosetto et al., "Synergistic antioxidant effect of catechin and malvidin 3-glucoside on free radicalinitated peroxidation of linoleic acid in micelles," Arch Biochem Biophys, vol. 408, pp. 239-245, 2002.

[18] P. Markakis, Anthocyanins as Food Color, New York: Academic Press, 1982.

[19] T. Y. Kim and K. H. Park, "Adsorption equilibrium and kinetics of gardenia blue on $\mathrm{TiO}_{2}$ photoelectrode for dye-sensitized solar cells," International Journal of Photoenergy, 2014.

[20] M. A. Khan and M. S. Akhtar, "Synthesis, characterization and applicable of sol-gel derived mesoporous $\mathrm{TiO}_{2}$ nanoparticles for dye-sensitized solar cells," Solar Energy, vol. 84, pp. 2195-2201, 2010.

[21] K. Fan, M. Liu, and T. Peng, "Effect of paste components on the properties of screen-printed porous $\mathrm{TiO}_{2}$ film for dye-sensitized solar cells," Renewable Energy, vol. 35, pp. 555-561, 2010.

[22] B. Guo and Z. Liu, "Sol gel derived photocatalytic porous $\mathrm{TiO}_{2}$ thin films," Surface Coating Technology, vol. 198, pp. 24-29, 2005.

[23] T. Miki, K. Nishizawa et al., "Preparation of thick $\mathrm{TiO}_{2}$ film with large surface area using aqueous sol with poly (ethylene glycol)," Journal Material Science, vol. 39, pp. 699-701, 2004.

[24] K. Kato and K. I. Nihara, "Roles of polyethylene glycol in evolution of nanostructured in $\mathrm{TiO}_{2}$ coatings," Thin Solid Films, vol. 298, pp. 76-82, 1997.

[25] R. E. Mistler and E. R. Twiname, Tape Casting Theory and Practice, Wiley-American Ceramic Society, 2000.

[26] S. K. Dhungel and J. G. Park, Renewable Energy, vol. 35, p. 2776 , 2010.

[27] H. H. Wang et al., "Preparation of nano-porous $\mathrm{TiO}_{2}$ electrodes for dye-sensitized solar cells," Journal of Nanomaterials, 2011

[28] M. N. Ramahan, Ceramic Processing and Sintering, Marcel Dekker Inc., 2003.

[29] N. Tasic and Z. Brankovic, "Effect of binder molecular weight on morphology of $\mathrm{TiO}_{2}$ films prepared by tape casting and their photovoltaic performance," Science of Sintering, pp. 365-372, 2012.
[30] G. P. Smestad and M. Gratzel, "Laboratory report : demonstrating electron transfer and nanotechnology: A natural dye-sensitized," Nanocrystalline Energy, 1998.

[31] J. M. R. C. Fernando and G. K. R. Senadeera, "Natural anthocyanins as photosensitizers for dye-sensitized solar devices," Curr Sci, vol. 95, pp. 663-666, 2008.

[32] S. Meng, J. Ren, and E. Kaxiras, "Natural dyes adsorbed on $\mathrm{TiO}_{2}$ nanowire for photovoltaic applications: enhanced light absorption and ultrafast electron injection," Nano Lett, vol. 8, no. 10, pp. 3266-3272, 2008.

[33] S. Ito et al., "Low-temperature synthesis of nanometer-sized crystalline $\mathrm{TiO}_{2}$ Particles and their photoinduced decomposition of formic acid,' Journal of Colloid and Interface Science, vol. 216, no. 1, pp. 59-64, 1999.

[34] Q. F. Zhang and G. Z. Cao, "Nanostructured photoelectrodes for dye-sensitized solar cells," Nano Today, vol. 6, no. 1, pp. 91-109, 2011.

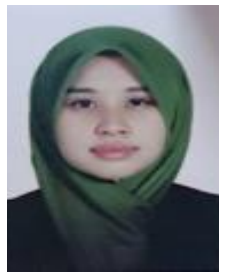

Arini Nuran Binti Zulkifili received the diploma in mechanical engineering in 2011 from Industrial University of Selangor, B.E degree in mechanical engineering in 2013 from Shibaura Institute of Technology. She is a M.E student now, with the Graduate School of Engineering and Science, Shibaura Institute of Technology.

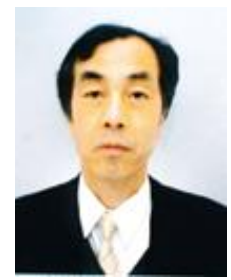

Akira Fujiki received his B.S. (1981), M.S. (1983), Ph.D. degrees (1997) in material engineering from WASEDA University, Tokyo, Japan. In 1983, he joined Nissan Motor CO., Ltd, where he was engaged in $\mathrm{R} \& \mathrm{D}$ of materials for automotive power-train system. Since 2009, he has been with the Faculty of College of System Engineering and Science at Shibaura Institute of Technology as a professor. His machineries. interests are mechanical and functional materials for 